\title{
AN INVESTIGATION OF GENERAL PERCEPTIONS OF THE IT WORKFORCE
}

\author{
David Munro, University of Wisconsin-Whitewater, munrod@uww.edu \\ Paul Ambrose, University of Wisconsin-Whitewater, ambrosep@uww.edu
}

\begin{abstract}
The perception that employees have of information technology or computing professionals is one that can potentially impact an array of issues from an organizations decisions to outsource IT or the employee turnover rate of IT professionals. While a significant amount of interest and research has looked at high school and college students perceptions as a factor in a student choosing or not choosing a technology major there has been little work of the perceptions of people in business. In order to establish a baseline of what the perceptions are of IT professionals, students in online MBA classes that consisted of both technical and non-technical persons were given the opportunity to state what their perceptions of technology professionals were in a discussion group. This paper presents an analysis of these comments and along with a discussion on the potential interventions that can be taken to alter such perceptions.
\end{abstract}

Keywords: Perceptions of Information Technology Professionals, Business User Perceptions, Artifact Analysis

\section{INTRODUCTION}

What does the world think of IT (Information Technology or Computing) professionals? Why does that matter? Anecdotal evidence suggests that IT professionals are geeks who do not listen, understand, or care about user needs, and have no interpersonal skills [7]. But do such negative opinions matter when IT professionals also get their work done? After all, it was IT professionals who over the past four decades have developed innovative technological solutions that revolutionized the way businesses and organizations function, and changed the way we live and work for the better, for most part [10].

An adverse perception of the IT function among the non-IT community both within and outside the organization has several negative consequences, but the following two overarching issues have profound impact, and determine how the IT function is organized and resourced in organizations. First, negative stereotypes within an organization can create an unproductive work environment for IT professionals [14]. Non-IT personnel and management may not trust or may be un-cooperative making it difficult for IT professionals to function effectively and efficiently. Resource availability to the IT function may take less precedence, and the innovators of the past may be relegated to office automatons of the future creating a high turnover career path. Second, a negative image would be detrimental to recruitment and retention of a quality workforce [6]. Computing programs continue to exhibit low enrollments in spite of a recent uptick in enrollment trends [15]. Even more alarming is the low enrollment of female and minorities and an adverse image will not encourage this key group to consider a computing career [7]. This in turn would lead to a shortage of IT professions and consequently the ability of organizations to be innovative and competitive [10]. It should be noted that the population whose perceptions were studied would not be the same as those deciding on what major to take in college, but rather would be an influential group that may be consulted in the form of family and friends of the family.

In this paper, we empirically investigate perceptions and stereotypes that IT professionals bring to the minds of people in the business community. Specifically, we undertake a qualitative study [4] by soliciting responses to a semi-structure protocol administered to a class of MBA students to probe their impressions of IT professionals. In the next section we highlight relevant literature applicable to our research. In the section following we detail the empirical study and discuss our findings. The final section presents the contribution and implications of this research, and our concluding thoughts. 


\section{Issues in Information Systems}

Volume 13, Issue 2, pp. 346-352, 2012

\section{RELEVANT LITERATURE}

The issue of the perception of technology professionals has been studied now for over a decade in an attempt to understand factors that can explain the decline of enrollments in computer related programs. Hence our review here is more a representative sampling than exhaustive, and to indicate the themes that were of concern in analyzing our data. Also of note, the main research methodology found in the existing literature is that of deductive reasoning using surveys.

Understanding and influencing the perceptions of the technology field is important when one realizes that in the absence of knowledge students fall back on their perceptions when choosing what field to pursue. A survey of students enrolled in a computer class found that "only about $28 \%$ expressed strong agreement or agreement that they understood what information technology professionals do. “ [5, p23]. An absence of such an understanding leads to the public being influenced by the media on the nature and characteristics of IT professionals and their careers [6]. For example García-Crespo et al [6] in a survey of literature of media portrayal of IT professionals found them depicted as nerdy, intelligent individuals skilled in mathematics and programming but lacking in social graces, likely to be loners who work long hours, and are boring, unethical, and poorly dressed.

The literature indicates that there is a difference found in perceptions based on gender. Among the college and high school students that were enrolled in an introduction MIS course females considered social image of greater importance then males in an online survey that was designed to examine factors that influenced their selection of a specific business major [3]. In another survey Stone \& Kitlan [13] found "that the gender differences in computing perceptions persist. Females were found to have significantly higher perceptions of computing, but this does not necessarily translate into a positive perception of computing-related careers." [13, p. 161]. Other surveys found that parents were the strongest influencers in student choice and perceptions [1].

It should be noted that not all the relevant literature is tied to those of students. In a survey examining the antecedents of an IT professional's degree of professional identification, that Brooks et al [2], found that public perceptions of the profession influenced the individual's perceptions of the profession of IT professionals.

\section{DATA COLLECTION AND ANALYSIS}

Graduate students enrolled in an online MBA class on IT policy and strategy course were asked as part of a module on the IT department to answer one of two discussion topics. The topic of relevance to this research was they were asked the following. "What are your perceptions of technology people? Are they people oriented? Are they able to relate to the rest of the business?" Students were asked to provide an original response to one of the two topics and also respond to at least two other students' comments. The open-ended semi-structured nature of these questions allowed the students to express their personal experiences and views. There were 70 students enrolled in the course of which $59(84 \%)$ participated in this topic. The great majority of the students were working full time.

The artifacts of these discussions provide a qualitative rich data source for analysis. The original 59 discussion posts were first read through to identify what characteristics and themes existed in the posts, and are shown in Table 1. Having identified these characteristics, the 59 discussion posts were evaluated and classified and the data were encoded. This encoding then allowed for an evaluation of the data more quantitatively and potentially identify patterns among combinations of the data characteristics that might exist. This approach of defining the characteristics to be encoded from the posts may for some readers unfamiliar with qualitative research appear to be strange. The approach is by design allowing the data to speak for itself [4]. This is parallel to the observing of physical phenomena, seeing some characteristics and patterns that are then studied more formally through the development and testing of hypotheses, as specified by the induction method of scientific reasoning [12]. 


\section{Issues in Information Systems}

Volume 13, Issue 2, pp. 346-352, 2012

Table 1: Characteristics and Themes Identified in the Student Discussions

\begin{tabular}{|l|}
\hline The gender of the author. \\
\hline Viewed the term "technology people" as a single group or subdivided into subsets of groups. \\
\hline $\begin{array}{l}\text { In cases where the term "technology people" was viewed as a single group the general } \\
\text { perspective of the group's social or people skills. }\end{array}$ \\
\hline $\begin{array}{l}\text { In cases where the term "technology people" was viewed as a single group the general } \\
\text { perspective of the group's business skills and understanding. }\end{array}$ \\
\hline Did the person state that their perceptions had changed over time. \\
\hline
\end{tabular}

\section{OBSERVATIONS FROM DATA}

While there was a great diversity among the respondent's postings (a sampling of comments available in Appendix A), they were in general agreement that there are stereotypes of technology workers among the general population, but interestingly, they didn't all accept the reality of the stereotype. In further evaluating the comments after they were encoded, while there was a great diversity of opinions expressed, several different themes emerged as follows:

\section{Majority treated "technology people" monolithically}

In addressing the question of “"'What are your perceptions of technology people?" the responses broke into three groups. The majority $(73 \%$, ) answered the question about the group as a whole with no distinction or clarification on what was meant by the term "technology people". However $24 \%$ broke the category into two or more different types of technology people. The remaining (3\%) participants remarks could not be classified into any meaningful subsets. Many of those who did identify subgroups tended to break it into two distinct groups with one group having good interpersonal skills and the other group having poor interpersonal skills. The breakdown between the groups was quite diverse. A sampling of the categorization of the two groups is in Table 2.

Table 2: Categorization of Subgroups Based on Interpersonal Skills

\begin{tabular}{|l|l|}
\hline Positive Interpersonal Skills & Negative Interpersonal Skills \\
\hline Non - Infrastructure & Infrastructure \\
\hline IT Managers & Lower levels \\
\hline Innovative type & Analyst type \\
\hline $\begin{array}{l}\text { Buffers between the functionally oriented and rest of } \\
\text { organization }\end{array}$ & Functionally oriented \\
\hline CIO & Local tech people \\
\hline Younger & Older \\
\hline
\end{tabular}

\section{Gender Differences}

Some have suggested that the perceptions of women about people in the technology field are responsible for the low number of women enrolled in technology degrees $[8,9,11]$. We found some support for this in our data. There were 23 females and 47 males enrolled in the online MBA course. Students were given a choice of two different topics to respond too. The participation rate in choosing this topic was $91 \%$ (21) for females and $81 \%$ (38) for males. While not conclusive, the participation rate indicates the issue was relatively more relevant to the females than the males in this study.

There was no difference by gender in the percentage of those who clearly did not treat the group monolithically. However among those who did treat the term "technology people" monolithically there were differences based on 


\section{Issues in Information Systems}

Volume 13, Issue 2, pp. 346-352, 2012

gender. As can be seen in Table 3 a higher percentage of females (57\%) than males (48\%) had the perception that technical people were lacking in their interpersonal skills. However the same data also shows females (36\% to 31\%) saw the technology group as having interpersonal skills. The difference is due to males' views being much more mixed (21\%) compared to females $(7 \%)$.

Table 3: Categorization of interpersonal skills of the monolithically treated discussions broken down by gender

\begin{tabular}{|c|r|r|r|r|}
\hline \multicolumn{5}{|c|}{ Have interpersonal skills } \\
\hline & \multicolumn{1}{|c|}{ Yes } & \multicolumn{1}{c|}{ Mixed } & \multicolumn{1}{c|}{ No } & \multicolumn{1}{c|}{ Total } \\
\hline Males & 9 & 6 & 14 & 29 \\
\hline \% of row & $31 \%$ & $21 \%$ & $48 \%$ & 1 \\
\hline Females & 5 & 1 & 8 & 14 \\
\hline \% of row & $36 \%$ & $7 \%$ & $57 \%$ & \\
\hline Total & 14 & 7 & 22 & 43 \\
\hline \% of row & $33 \%$ & $16 \%$ & $51 \%$ & \\
\hline
\end{tabular}

As can be seen in Table 4 a higher percentage of males (41\%) than females $(21 \%)$ had the perception that that technical people have business skills and understanding. In this area females were much more mixed (21\%) in their stated perceptions compared to males (3\%).

Table 4: Categorization of business understanding and skills of the monolithically treated discussions broken down by gender

\begin{tabular}{|c|r|r|r|r|r|}
\hline \multicolumn{7}{|c|}{ Have business understanding and skills } \\
\hline & \multicolumn{1}{|c|}{ Yes } & \multicolumn{1}{c|}{ Mixed } & \multicolumn{1}{c|}{ No } & Unknown & Total \\
\hline Males & 12 & 1 & 10 & 6 & 29 \\
\hline \% of row & $41 \%$ & $3 \%$ & $34 \%$ & $21 \%$ & \\
\hline Females & 3 & 3 & 5 & 3 & 14 \\
\hline \% of row & $21 \%$ & $21 \%$ & $36 \%$ & $21 \%$ & \\
\hline Total & 15 & 4 & 15 & 9 & \\
\hline \% of row & $35 \%$ & $9 \%$ & $35 \%$ & $21 \%$ & \\
\hline
\end{tabular}

The reason as to why females are more nuanced or mixed in their perception of business understanding and skills, while more males are more nuanced or mixed about interpersonal skills is unclear. It does however provide further support for there being gender differences in the perception of people in the technology fields.

\section{Perceptions changed}

It was encouraging to find that $19 \%$ of the respondents reported that their perceptions had changed over time in ways that could be perceived as positive. An examination of Tables 5 and 6 clearly demonstrate this fact. Examination of this group was of particular interest to see if their comments could provide some insight into the process of changing perceptions. The two main themes that came from these were (1) Some have changed their perception as they have personally interacted with technology people, (2) Over the years the technology people have changed and have moved away from the stereotypes. 


\section{Issues in Information Systems}

Volume 13, Issue 2, pp. 346-352, 2012

Table 5: Categorization of interpersonal skills of the monolithically treated discussions broken down by indication of views having changed

\begin{tabular}{|c|r|r|r|r|}
\hline \multicolumn{5}{|c|}{ Have interpersonal skills } \\
\hline & \multicolumn{1}{|c|}{ Yes } & \multicolumn{1}{c|}{ Mixed } & \multicolumn{1}{c|}{ No } & Total \\
\hline Views have changed & 8 & 2 & 0 & 10 \\
\hline \% of row & $80 \%$ & $20 \%$ & $0 \%$ & 33 \\
\hline Views have not changed & 6 & 5 & 22 & \\
\hline \% of row & $18 \%$ & $15 \%$ & $67 \%$ & 43 \\
\hline Total & 14 & 7 & 22 & \\
\hline \% of row & $33 \%$ & $16 \%$ & $51 \%$ & \\
\hline
\end{tabular}

Table 6: Categorization of business understanding and skills of the monolithically treated discussions broken down by indication of views having changed

\begin{tabular}{|c|c|c|c|c|c|}
\hline \multicolumn{6}{|c|}{ Have business understanding and skills } \\
\hline & Yes & Mixed & No & Unknown & Total \\
\hline Views have changed & 7 & 0 & 0 & 3 & 10 \\
\hline$\%$ of row & $70 \%$ & $0 \%$ & $0 \%$ & $30 \%$ & \\
\hline Views have not change & 8 & 4 & 15 & 6 & 33 \\
\hline$\%$ of row & $24 \%$ & $12 \%$ & $45 \%$ & $18 \%$ & \\
\hline Total & 15 & 4 & 15 & 9 & 43 \\
\hline$\%$ of row & $35 \%$ & $9 \%$ & $35 \%$ & $21 \%$ & \\
\hline
\end{tabular}

\section{CONTRIBUTION, IMPLICATIONS AND CONCLUDING REMARKS}

This research, while primarily consistent with the findings of past research on this topic, provides additional support for a difference of perceptions by gender. Also, an inductive reasoning method of inquiry adopted in this research is free of any unintended bias that may be introduced in the wording of any data gathering protocols used in deductive reasoning based methodology.

The fact that $73 \%$ of the respondents treated the term "technology people" monolithically indicates that there is a need to educate the public about the diversity of information technology careers. Perhaps the field could collectively undertake interventions to positively market the diversity of the computing field and careers.

The existence of gender differences indicates that efforts to change perspectives must be multifaceted. One of the main ways to change perceptions may be simply organizing more activities to allow the public to interact with people in the technology field. In education settings this may involve having upper level technology students providing some ways of interacting with freshmen in a positive and socially natural way. For example helping students install software or wireless networks for students studying infrastructure issues. The gender differences also highlight the need for women IT professionals to be more active in promoting the field, and also serve as mentors to other potential female entrants to the field.

In conclusion, the field of IT still needs to proactively address its image and can take some consolation in the fact that people who perceptions did change, changed in a favorable direction. 


\section{Issues in Information Systems}

Volume 13, Issue 2, pp. 346-352, 2012

\section{REFERENCES}

1. Babin, R., Grant, K. A., and Sawal, L. (2010) Identifying Influencers in High School Student ICT Career Choice. Information Systems Education Journal 8, 1-18

2. Brooks, N. G., Riemenschneider, C. K., Hardgrave, B. C., and O'Leary-Kelly, A. M. (2011) IT professional identity: needs, perceptions, and belonging. European Journal of Information Systems 20, 87-102

3. Cho, J., Jones, S., and Olsen, D. (2008) An Exploratory Study on Factors Influencing Major Selection Issues in Information Systems 9, 168-175

4. Cobin, J., and Strauss, A. (2007) Basics of Qualitative Research: Techniques and Procedures for Developing Grounded Theory, Sage Publications, Thousand Oaks, CA

5. Courte, J., and Bishop-Clark, C. (2007) Student perceptions of computing majors and professionals. $J$. Comput. Sci. Coll. 23, 21-27

6. Garcia-Crespo, A., Colomo-Palacios, R., Gomez-Berbis, J., and Tovar-Caro, E. (2008) The IT Crowd: Are We Stereotypes? IT Professional Magazine 10, 24

7. Grant, D. M., Knight, L. V., and Steinbach, T. A. (2007) Young Women's Misinformation Concerning IT Careers: Exchanging One Negative Image for Another. Informing Science 10, 91-106

8. He, J., and Freeman, L. A. (2010) Are Men More Technology-Oriented Than Women? The Role of Gender on the Development of General Computer Self-Efficacy of College Students. Journal of Information Systems Education 21, 203-212

9. Nielsen, S. H., Von Hellens, L. A., and Beekhuyzen, J. (2004) Challenge or Chaos: A Discourse Analysis of Women's Perceptions of the Culture of Change in the IT Industry. Issues in Informing Science \& Information Technology 1, 715-727

10. Paul, M. I. (2007) IT, We Have a Problem! Part II. Computerworld 41, 36

11. Rosenbloom, J. L., Ash, R. A., Dupont, B., and Coder, L. (2008) Why are there so few women in information technology? Assessing the role of personality in career choices. Journal of Economic Psychology 29, 543-554

12. Rubin, A., and Babbie, E. R. (2010) Research methods for social work, Brooks Cole, Belmont, CA

13. Stone, J. A., and Kitlan, D. P. (2010) Factors impacting student perceptions of computing and CIS majors. J. Comput. Small Coll. 25, 156-163

14. Wentling, R., and Thomas, S. (2009) Workplace Culture That Hinders and Assists The Career Development of Women in Information Technology. Information Technology, Learning, and Performance Journal 25, 25-42

15. Zweben, S. (2011) Computing Degree and Enrollment Trends. In Computing Research News Vol. 23 


\section{Issues in Information Systems}

Volume 13, Issue 2, pp. 346-352, 2012

\section{APPENDIX A - A sampling of comments that reflected the participant's perceptions}

- "friendly people, communication skills seem to lack, focused on bettering the technology for the company, rather than assisting others" "intelligent, problem solving, focused, socially awkward, yet fairly people friendly"

- "Typically, these individuals are focused mainly on technical aspects of work, and all other aspects (financial, efficiency, innovation and especially socio-political) take a backseat."

- "Tech support should be people oriented, many I have met are personable and good at their jobs. Programmers are programmers, don't bring them to too many meetings."

- "I perceive tech people as being overcomplicated, insular, peculiar in their way and explanations."

- "I've worked with a wide variety of IT people and they all have had different personalities. I know a lot of people who just think of IT people as socially awkward. However I've come across those who are a bit socially awkward and those who have become good friends of mine. I definitely think they are people oriented. It would be awful hard to work with and resolve other's problems if they weren't able to communicate effectively." 